九州大学学術情報リポジトリ

Kyushu University Institutional Repository

\title{
Root Penetration Ability of Vietnamese Tranditional Upland Rice Varieties
}

Nhan, Dang Quy

Graduate School of Bioresource and Bioenvironmental Sciences, Kyushu University

Thaw, Soe

Graduate School of Bioresource and Bioenvironmental Sciences, Kyushu University

Matsuo, Naoki

Graduate School of Bioresource and Bioenvironmental Sciences, Kyushu University

Mochizuki, Toshihiro

Faculty of Agriculture, Kyushu University

https://doi.org/10.5109/9236

出版情報: 九州大学大学院農学研究院紀要. 51 (2)，pp. 245-249，2006-10-27. Faculty of Agriculture, Kyushu University

バージョン :

権利関係 : 


\title{
Root Penetration Ability of Vietnamese Traditional Upland Rice Varieties
}

\author{
Dang Quy NHAN ${ }^{1}$, Soe THAW ${ }^{1}$, Naoki MATSUO ${ }^{1}$, \\ and Toshihiro MOCHIZUKI*
}

\author{
Laboratory of Agricultural Ecology, Division of Agricultural Ecology, Department of Plant Resources, \\ Faculty of Agriculture, Kyushu University, Fukuoka 811-2307, Japan \\ (Received June 30, 2006 and accepted July 24, 2006)
}

\begin{abstract}
Drought is the major cause of low yield of rice grown in the rainfed uplands, where has aerobic and strong soil because of water deficit. Root penetration ability (RPA) through compacted soil layers or hardpans has been recognized as an important breeding objective for improvement of drought resistance in rice. The study was conducted to evaluate RPA of Vietnamese traditional upland rice varieties comparing with rice cultivars belonged to different ecotypes. Root penetration ability was evaluated through shallow $(5 \mathrm{~cm})$ and deep $(10 \mathrm{~cm})$ wax layers in the plastic tube. Root penetration rate $(\mathrm{RPR})$, that is the ratio of the number of roots penetrated wax layers (PRN) to the total number of roots (TRN), was assumed to be an index of PRA. Although RPR through shallow wax layer was higher than that through deep wax layer, higher correlation between them was found $(\mathrm{r}=79 * *)$. Japonica upland showed the superior RPA than other ecotypes. While, there was no significant difference between RPR of Vietnamese traditional upland and other Indica upland rice. Significant correlations between RPR and TRN, PRN, root thickness (RT) and root dry weight (RDW) in deep wax layers treatment were found $\left(r=-0.41^{* *}, r=0.82^{* *}, r=0.63^{* *}\right.$, and $r=$ $0.51^{* *}$, respectively).
\end{abstract}

\section{INTRODUCTION}

The world's annual cultivating area of rice is about 148 million ha, of which about $12 \%$ is rainfed upland (Khush, 1997). Although the production of upland rice is important to the agricultural economy of many countries, upland rice contributes only $4 \%$ of the total rice production, because of its low yield with an average 1 ton $\mathrm{ha}^{-1}$ (Dat, 1986). Also in Vietnam, upland rice is now still grown on about 0.45 million ha (Hong et al., 1999), and is commonly cultivated as shifting cultivation, and slash and burn occupied practice by the ethnic minority who lived in the mountainous area. There are many traditional upland rice varieties cultivated in this area, but the yield varied from 0.6 to 2.0 tons ha-1 (Hong et al., 1999).

Drought stress is a major constraint to the productivity of rice in upland ecosystem (Nguyen et al., 1997). In these areas, soils are commonly aerobic and may be strong due to lack of water. Strong soil causes a serious problem in crop production, because it restrict access of the root system to water and nutrient, and so decrease crop yield (Clark et al., 2003). Rice plant with a deep root system is therefore beneficial in avoiding water stress by absorbing water from deep soil layers (Clark et al., 2002). Root penetration ability (RPA) through compacted soil layers or hardpans has been recognized as an important breeding objective for improvement of drought resistance in rice (Hanson et al., 1990)

\footnotetext{
1 Laboratory of Agricultural Ecology, Division of Agricultural Ecology, Department of Plant Resources, Graduate School of Bioresource and Bioenvironmental Sciences, Kyushu University.

* Corresponding author (E-mail: mochizuki@farm.kyushu-u. ac.jp)
}

For screening root traits in rice, several techniques in laboratory have been developed. The method using thin wax layers instead of soil hardpans for measuring RPA was proposed by Yu et al. (1995). They found that upland rice varieties showed better RPA than lowland varieties. This method was subsequently used by many researchers (Ali et al., 2000; Babu et al., 2003; Price et al., 2000; Ray et al., 1996; Zheng et al., 2000) to identify QTLs controlling RPA. Kubo et al. (2004) modified the method that is $3 \mathrm{~mm}$ wax layer was installed at $10 \mathrm{~cm}$ of Polyvinyl Chloride (PVC) tube $(6 \mathrm{~cm}$ diameter and $15 \mathrm{~cm}$ height) filled with vermiculite to assess RPA of a recombinant inbred line in wheat (Triticum turgidum L. var. durum). This method is considered easier to investigate RPA of rice .

Assessment of huge genotypic difference on RPA and root traits is an initial step to breed new rice variety with drought resistance. This study was therefore conducted to evaluate RPA of Vietnamese traditional upland rice varieties comparing with rice cultivars belonged to other groups.

\section{MATERIALS AND METHODS}

This study was conducted in the phytotron of Kyushu University from July to September, 2005.

\section{Experiment 1. The relations between the hardness of wax layers and the RPA}

Six rice varieties were used to test for the RPA through wax layers with different hardness. Beo dien and Ep hat dai are Vietnamese traditional upland, Sensho and Hataminori Mochi are Japonica upland, and Nipponbare and Koshihikari are Japonica lowland rice varieties.

Wax layers with different strength were made by 
mixing paraffin and vaseline in different proportions. The mixture of each six paraffin concentrations (30, 40, 50, 60, 70 and 80\%) and vaseline was well blended. The mixture was heated at $80^{\circ} \mathrm{C}$ until the wax was completely melted, and then poured into PVC tubes (height: $70 \mathrm{~mm}$ or $3 \mathrm{~mm}$; diameter: $6 \mathrm{~cm}$ ), and allowed to solidify at room temperature. Mechanical strength of wax layers which $70 \mathrm{~mm}$ of height were measured by using the soil penetrometer (DIK-5561, Daikirikakogyo Co., Ltd. Tokyo, Japan) at $25^{\circ} \mathrm{C}$.

Wax layers ( $3 \mathrm{~mm}$ thick and $6 \mathrm{~cm}$ in diameter) of each formula were installed at $10 \mathrm{~cm}$ from the top of PVC tube ( $15 \mathrm{~cm}$ height and $6 \mathrm{~cm}$ in diameter). The gaps between wax layers and the side of the tube were sealed by melted wax. The spaces in the tube are filled with nutrient vermiculite and watered. The tubes were covered at the bottom with plastic screen mesh $(1 \mathrm{~mm}$ spacing) therefore vermiculite could be held inside of the tubes. Chemical fertilizer $\left(4 \% \mathrm{NH}_{4} ; 4 \% \mathrm{P}_{2} \mathrm{O}_{5} ; 2.5 \%\right.$ $\mathrm{MgPO}_{4} ; 4 \% \mathrm{~K}_{2} \mathrm{O}$ ) was applied with $0.73 \mathrm{~g}$ per tube. All tubes were placed in the water bath $(1 \mathrm{~m} \times 0.9 \mathrm{~m} \times$ $0.3 \mathrm{~m}$ ) and the water surface was maintained at a level just below the position of the wax layers. Seeds of all varieties were soaked in water at $30^{\circ} \mathrm{C}$ for 3 days. A single seed of each variety was sown per tube. Plants were grown in the growth cabinet at $25^{\circ} \mathrm{C}, 70 \%$ relative humidity and $250-300 \mu \mathrm{mol} \mathrm{m}{ }^{-2} \mathrm{~s}^{-1}$ light intensity for $12 \mathrm{~h}$ day $^{-1}$, and were watered every three days.

At 21 days after sowing (DAS), the total number of roots (TRN) and the number of roots that penetrated the wax layer (PRN) in each plant was counted. The root penetration rate (RPR) indicating the RPA was calculated as the ratio of PRN to TRN.

\section{Experiment 2. Varietal difference of the RPA}

Seventy two rice including 6 varieties used in Exp.1 were tested. Of which, 23 were Vietnamese traditional upland, 13 were Japonica upland, and 17 were Japonica lowland rice varieties. The remaining were 19 Indica upland rice varieties collected from IRRI and several other countries (Table 1).

A wax of $60 \%$ paraffin (penetrometer resistance was $1.5 \mathrm{MPa}$ ) was used in this experiment. The wax layers were installed in tube $(15 \mathrm{~cm}$ height, and $6 \mathrm{~cm}$ in diameter) from the top at $5 \mathrm{~cm}$ and $10 \mathrm{~cm}$ in the shallow and the deep hardpan treatment, respectively. The screening system was prepared as described detail in the Exp.1.

Table 1. Plant materials

\begin{tabular}{|c|c|c|c|c|c|c|c|}
\hline Name & Origin & Cultural type & Variety type & Name & Origin & Cultural type & Variety type \\
\hline Beo dien & Vietnam & Upland & Traditional indica & LC-90-12 & IRRI & Upland & Indica \\
\hline Beo san van & Vietnam & Upland & Traditional indica & LP93-1 & IRRI & Upland & Indica \\
\hline Do meo & Vietnam & Upland & Traditional indica & UPLR1-7 & IRRI & Upland & Indica \\
\hline Ep hat dai & Vietnam & Upland & Traditional indica & WAB 96-1-1 & IRRI & Upland & Indica \\
\hline Ep hat den & Vietnam & Upland & Traditional indica & $63-104$ & Ivory cost & Upland & Indica \\
\hline Ep hat to & Vietnam & Upland & Traditional indica & 8 FA337-1 & IRRI & Upland & Indica \\
\hline Ep hat tron & Vietnam & Upland & Traditional indica & Azucena & Philippines & Upland & Japonica \\
\hline Khau kai & Vietnam & Upland & Traditional indica & Hataminori Mochi & Japan & Upland & Japonica \\
\hline Khau ken & Vietnam & Upland & Traditional indica & Minamihata Mochi & Japan & Upland & Japonica \\
\hline Khau linh & Vietnam & Upland & Traditional indica & Owarihata Mochi & Japan & Upland & Japonica \\
\hline Khau van & Vietnam & Upland & Traditional indica & Rikuto Norin 6 & Japan & Upland & Japonica \\
\hline Mo do & Vietnam & Upland & Traditional indica & Rikuto Norin 12 & Japan & Upland & Japonica \\
\hline Mua chua & Vietnam & Upland & Traditional indica & Rikuto Norin 22 & Japan & Upland & Japonica \\
\hline Nep bao lac & Vietnam & Upland & Traditional indica & Rikuto Norin 24 & Japan & Upland & Japonica \\
\hline Nep ha giang & Vietnam & Upland & Traditional indica & Rikuto Norin Mochi 1 & Japan & Upland & Japonica \\
\hline Nep khau non & Vietnam & Upland & Traditional indica & Rikuto Norin Mochi 8 & Japan & Upland & Japonica \\
\hline Nep meo & Vietnam & Upland & Traditional indica & Rikuto Norin Mochi 18 & Japan & Upland & Japonica \\
\hline Nep nuong trang & Vietnam & Upland & Traditional indica & Rikuto Norin Mochi 20 & Japan & Upland & Japonica \\
\hline Nep xiem & Vietnam & Upland & Traditional indica & Rikuto Norin Mochi 25 & Japan & Upland & Japonica \\
\hline Ple chong po & Vietnam & Upland & Traditional indica & Akebono & Japan & Lowland & Japonica \\
\hline Thoc te duoi bo & Vietnam & Upland & Traditional indica & Chiyonishiki & Japan & Lowland & Japonica \\
\hline Vien cham & Vietnam & Upland & Traditional indica & Sekisho & Japan & Lowland & Japonica \\
\hline Xe liem & Vietnam & Upland & Traditional indica & Toyonishiki & Japan & Lowland & Japonica \\
\hline Columbial & Colombia & Upland & Indica & Domannaka & Japan & Lowland & Japonica \\
\hline Khao Dam & Laos & Upland & Indica & Haenuki & Japan & Lowland & Japonica \\
\hline Kinandang Patong & Philippines & Upland & Indica & Miyazaki Zairai & Japan & Lowland & Japonica \\
\hline Ma Hae & Thailand & Upland & Indica & Aikoku & Japan & Lowland & Japonica \\
\hline Sensho & Japan & Upland & Indica & Akitsuho & Japan & Lowland & Japonica \\
\hline CI PAD141 & IRRI & Upland & Indica & Hinohikari & Japan & Lowland & Japonica \\
\hline CT6510-24-1-2 & IRRI & Upland & Indica & Kibinohana & Japan & Lowland & Japonica \\
\hline Dourado Precode & Brazil & Upland & Indica & Lemont & Japan & Lowland & Japonica \\
\hline IR47686-30-3-2 & IRRI & Upland & Indica & Takara & Japan & Lowland & Japonica \\
\hline IR57920 & IRRI & Upland & Indica & Koshihikari & Japan & Lowland & Japonica \\
\hline IR715-19-1-1 & IRRI & Upland & Indica & Shirobeniya & Japan & Lowland & Japonica \\
\hline IRAT 117 & Ivory cost & Upland & Indica & Shinriki & Japan & Lowland & Japonica \\
\hline LAC23 & Liberia & Upland & Indica & Nipponbare & Japan & Lowland & Japonica \\
\hline
\end{tabular}


The data of the TRN, PRN, were recorded at 21 DAS, and the RPR was calculated. Three penetrated roots were randomly collected from each plant for root thickness (RT) measurement. Root thickness was measured at $1 \mathrm{~cm}$ from the root tip. Root dry weight (RDW) was measured after drying at $70^{\circ} \mathrm{C}$ for 72 hours.

Each experiment was conducted in randomized complete block designed with 3 replications. Data were analyzed with the statistical procedure of SAS (SAS Institute, Cary, NC). Analysis of variance was performed with the PROC ANOVA procedure and correlations were obtained with the PROC CORR procedure (Pearson correlations).

\section{RESULTS}

\section{Penetrometer resistance of wax layers}

The strength of various wax layers was showed in Fig. 1. Penetrometer resistance increased with the percentage of paraffin in the wax layers, reaching $4.5 \mathrm{MPa}$ at $80 \%$ paraffin concentration of wax layer.

\section{Effect of wax layer strength to RPR}

Fig. 2 showed that RPR of every variety used decreased as the hardness of wax layer increased. There was no variety that penetrated the wax layer of $70 \%$. Varietal differences were detected at every hardness of wax layers except 70\% paraffin. RPR of Sensho and Hataminori Mochi were 37.3 and $32.9 \%$, respectively, while that of the others ranged from 8.4 to $16.8 \%$ at the wax layer of $60 \%$ paraffin.

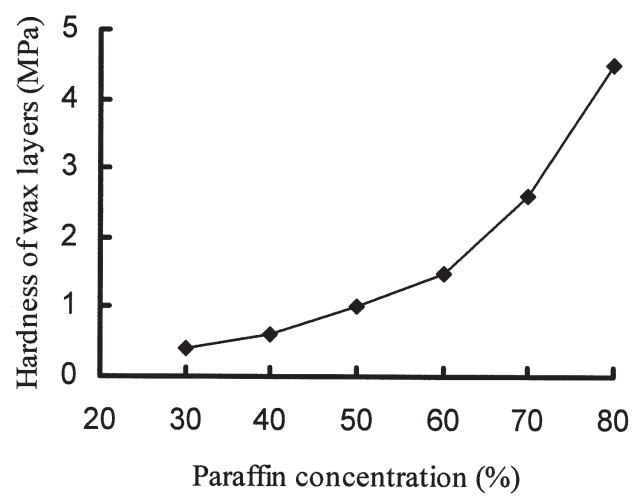

Fig. 1. Effect of paraffin concentration on hardness of wax layers.

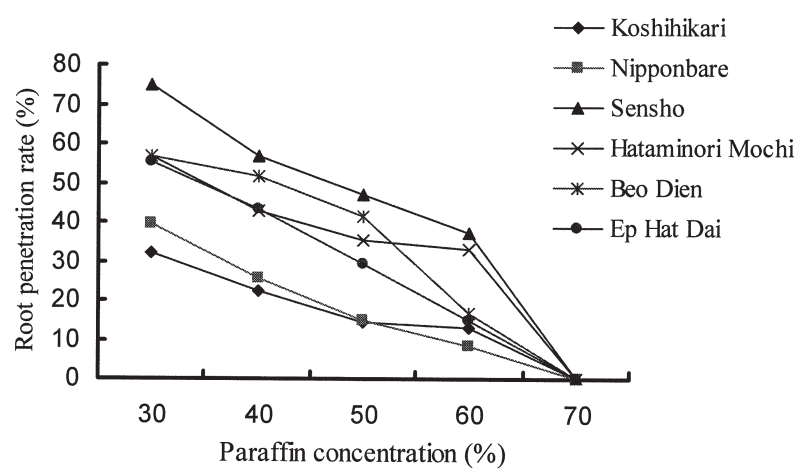

Fig. 2. Effect of paraffin concentration to the root penetration rate in rice.

\section{Varietal differences of root penetration ability and some root traits.}

The mean value of 4 rice groups on the root traits in both shallow and deep hardpan treatment are summarized in Table 2. Variation on all root traits was found between 4 groups. Japonica lowland had the highest TRN both in shallow hardpans (TRNS) and deep hardpans (TRND) with means of 28.5 and 30.3, respectively. The lowest mean value of TRNS and TRND were found in Indica upland (18.7) and Vietnamese traditional upland (20.9), respectively. PRN through shallow hardpans (PRNS) and PRN through deep hardpans (PRND) of Japonica upland group were higher than the others with mean of 6.3 and 6.7, respectively. Japonica upland had both the highest RPR through shallow hardpan (RPRS) of 31.7 and RPR through deep hardpan (RPRD) of 28.2. The lowest of these values were found in Japonica lowland with 18.6 of RPRS and 10.4 of RPRD, respectively. In all upland groups RT were 2-fold bigger than that in lowland rice. Japonica, Vietnamese traditional, and Indica upland had $0.71,0.73$ and $0.71 \mathrm{~mm}$ of RT, respectively. While, Japonica lowland had 0.36 of RT. Japonica upland rice had the highest RDW (0.11) and the lowest (0.06) was found in Japonica lowland.

In all groups the relationship between RPR through shallow and deep hardpan were found a positive significant correlation coefficient with $\mathrm{r}=0.79 * *$ (Fig. 3).

Relations between RPR and other root traits in deep hardpan treatment were given in the Fig. 4. RPR positively correlated with PRN, RT, and RDW, but negatively associated with TRN. The correlation coefficient of TRN, PRN, RT and RDW with RPRD were $\mathrm{r}=-0.41^{* *}$, $\mathrm{r}=0.82^{* *}, \mathrm{r}=0.63^{* *}$ and $\mathrm{r}=0.51^{* *}$, respectively.

Table 2. Variation on root traits among 4 varietal groups

\begin{tabular}{|c|c|c|c|c|c|c|c|c|}
\hline Group & TRNS & PRNS & RPRS & TRND & PRND & RPRD & RTD & RDWD \\
\hline & & & $\%$ & & & $\%$ & $\mathrm{~mm}$ & g \\
\hline Japonica upland & $20.2 \mathrm{c}$ & $6.3 \mathrm{a}$ & $31.7 \mathrm{a}$ & $24.5 \mathrm{~b}$ & $6.7 \mathrm{a}$ & $28.2 \mathrm{a}$ & $0.71 \mathrm{a}$ & $0.11 \mathrm{a}$ \\
\hline Vietnamese traditional upland & $22.2 \mathrm{~b}$ & $5.6 \mathrm{~b}$ & $26.1 \mathrm{~b}$ & $20.9 \mathrm{~d}$ & $4.3 \mathrm{~b}$ & $20.5 \mathrm{~b}$ & $0.73 \mathrm{a}$ & $0.10 \mathrm{~b}$ \\
\hline Indica upland & $18.7 \mathrm{c}$ & $4.9 \mathrm{c}$ & $26.6 \mathrm{~b}$ & $22.4 \mathrm{c}$ & $4.0 \mathrm{~b}$ & $19.3 \mathrm{~b}$ & $0.71 \mathrm{a}$ & $0.10 \mathrm{~b}$ \\
\hline Japonica lowland & $28.5 \mathrm{a}$ & $5.2 \mathrm{bc}$ & $18.6 \mathrm{c}$ & $30.3 \mathrm{a}$ & $3.1 \mathrm{c}$ & $10.4 \mathrm{c}$ & $0.36 \mathrm{~b}$ & $0.06 \mathrm{c}$ \\
\hline
\end{tabular}

TRNS, PRNS and RPRS: total root number, penetrated root number and root penetration rate through shallow wax layers, respectively. TRND, PRND, RPRD, RTD and RDWD: total root number, penetrated root number, root penetration rate, root thickness and root dry weight through deep wax layers, respectively. ${ }^{1}$ Means with the same latter in a column are not significant. 


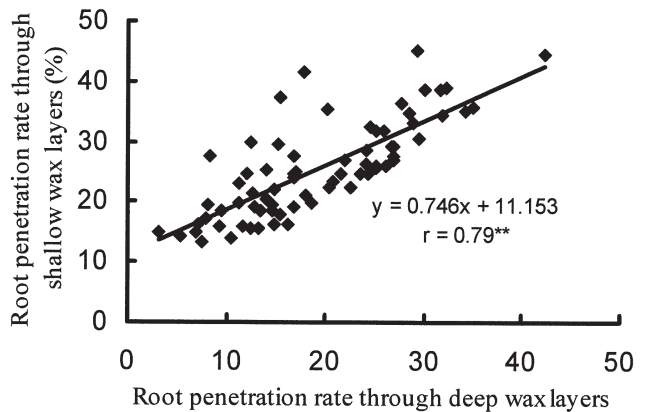

(\%)

Fig. 3. Relationship between root penetration rate through shallow and deep wax layers; $* *$ Significant at $\mathrm{P}=0.01$.

\section{DISCUSSION}

So far, many experiments have been suggested that the ability of rice to penetrate compacted soil is linked with capacity to develop several root traits such as: few thick (fibrous), long root axes, and root biomass (Babu et al., 2001; Ekanayake et al., 1985; Samson et al., 2002; Yu et al., 1995). However, in laboratory the effect of hardpan position to root penetration in rice has not been reported. In this study, two treatments of hardpan position (at 5 and $10 \mathrm{~cm}$ ) from the soil surface were conducted to screen RPA in rice cultivars. Although the RPR through shallow hardpan was higher than that through deep hardpan (Table 3), there was a positive correlation coefficient between them (Fig. 3). In both treatments, RPRS and RPRD were highest in Japonica upland and lowest in Japonica lowland. There was no significant difference between those in Indica and Vietnamese traditional upland. In general, RPR of rice was highly associated with the PRN (Babu et al., 2001) as it also found in this study. Japonica upland usually had superior root traits than the other rice ecotypes (Yu et al., 1995 and Babu et al., 2001).

Genotypic variation of root morphology has been reported (Babu et al., 2001; Thanh et al., 1999; Yu et al., 1995). Yu et al. (1995) suggested there was a significant genotypic variation existed on RPA among rice cultivars. They indicated that upland-adapted Japonica varieties had higher root penetration index than the lowland-adapted Indica varieties. In general, Japonica adapted-upland and traditional-upland rice cultivars have well developed root system with inherent higher RPA (Thanh et al., 1999; Yoshida, 1982; Yu et al., 1995). However, Babu et al. (2001) reported that an Indica accession (IR 58821-23-B-1-2-1) and traditional varieties (Kallurundaikar and Norungan) had higher penetration index, than even Japonica accessions in their experiment.

Root penetration through compacted soil layers or hardpans has been recognized as an important breeding objective for improvement of drought resistance in rice (Hanson et al., 1990). As observed in this research, Japonica upland had higher RPR than other rice groups (Table 2). Japonica lowland had higher TRN, however they showed weak RPR. It was suggested that greater TRN did not contribute to the ability of rice roots to penetrate compacted soil as described by Babu et al. (2001) and Nguyen et al. (1997).

Rice varieties which had thick root could penetrate compacted soil to reach the water in depth (Ekanayake et al., 1985; Veen, 1982; Yoshida, 1982; Yu et al., 1995).
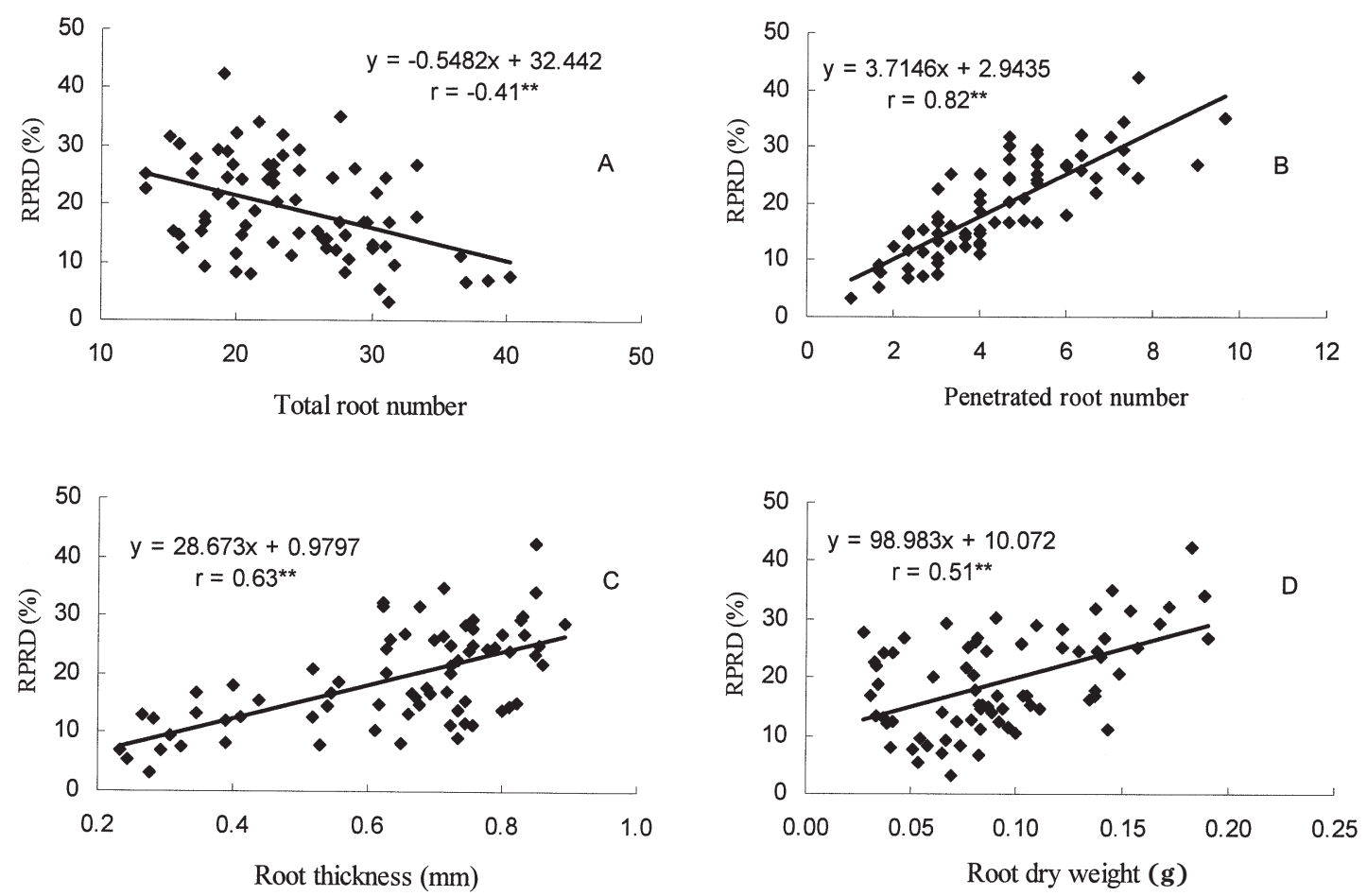

Fig. 4. Relationship between root penetration rate through deep wax layers and: A. Total root number; B. Penetrated root number; C. Root thickness; D. Root dry weight. ** Significant at P =0.01. 
In our study, all upland rice groups had superior root thickness value than lowland rice (Table 2). There was a positive correlation coefficient between RTD and RPRD (Fig. 4). Babu et al. (2001) reported that root biomass was a good indicator of drought avoidance in upland rice. Our result revealed that the RDW of upland rice was higher than that of lowland rice (Table 2). Further the positive correlation coefficient between RDW and RPRD was found.

\section{REFERENCES}

Ali, M. L., M. S. Pathan, J. Zhang, G. Bai, S. Sarkarung and H. T. Nguyen 2000 Mapping QTLs for root traits in a recombinant inbred population from two indica ecotypes in rice. Theoretical and Applied Genetics, 101: 756-766

Babu, R. C., B. D. Nguyen, V. Chamarerk, P. Shanmugasundaram, P. Chezhian, P. Jeyaprakash, S. K. Ganesh, A. Palchamy, S. Sadasivam, S. Sarkarung, L. J. Wade and H. T. Nguyen 2003 Genetic analysis of drought resistance in rice by molecular markers: Association between secondary traits and field performance. Crop Sci, 43: 1457-1469

Babu, R. C., H. E. Shashidhar, J. M. Lilley, N. D. Thanh, J. D. Ray, S. Sadasivam, S. Sarkarung, J. C. O'Toole and H. T. Nguyen 2001 Variation in root penetration ability, osmotic adjustment and dehydration tolerance among accessions of rice adapted to rainfed lowland and upland ecosystems. Plant Breeding, 120: 233-238

Clark, L. J., R. E. Cope, W. R. Whalley, P. B. Barraclough and L. J. Wade 2002 Root penetration of strong soil in rainfed lowland rice: comparison of laboratory screens with field performance. Field Crop Res, 76: 189-198

Clark, L. J., W. R. Whalley and P. B. Barraclough 2003 How do roots penetrate strong soil? Plant Soil, 255: 93-104

Dat, T. T. 1986 An overview of upland rice in the word. Progress in upland rice research. Proc. Jakarta conference. IRRI, Losbanos, Philippines.

Ekanayake, I. J., J. C. Otoole, D. P. Garrity and T. M. Masajo 1985 Inheritance of Root Characters and Their Relations to Drought Resistance in Rice. Crop Science, 25: 927-933

Hanson, A. D., W. J. Peacock, L. T. Evans, C. J. Arntzen and G. S. Khush 1990 Drought Resistance in Rice. Nature, 345: $26-27$
Hong, H. H., B. Coutoirs and D. Q. Nhan 1999 On farm trial of some promising upland rice varieties in the rainy season 1998 at Chodon district, Backan province, Vietnam. In: Upland rice research consortium in South, Southeast Asia (phase III). p. 3-4. Second annual report may 1998-April 1999, Losbanos, Philippines.

Khush, G. S. 1997 Origin, dispersal, cultivation and variation of rice. Plant Molecular Biology, 35: 25-34

Kubo, K., K. Jitsuyama, N. Watanabe and K. Iwana 2004 Analysis of the relationship between semi-dwarf gene and root penetration ability using recombinant inbred lines and near-isogenic lines in wheat. Jpn. J. Crop Sci., 73 Extra issue 2: 77

Nguyen, H. T., R. C. Babu and A. Blum 1997 Breeding for drought resistance in rice: Physiology and molecular genetics considerations. Crop Sci, 37: 1426-1434

Price, A. H., K. A. Steele, B. J. Moore, P. B. Barraclough and L. J. Clark 2000 A combined RFLP and AFLP linkage map of upland rice (Oryza sativa L.) used to identify QTLs for root-penetration ability. Theoretical and Applied Genetics, 100: $49-56$

Ray, J. D., L. Yu, S. R. McCouch, M. C. Champoux, G. Wang and H. T. Nguyen 1996 Mapping quantitative trait loci associated with root penetration ability in rice (Oryza sativa L). Theoretical and Applied Genetics, 92: 627-636

Samson, B. K., M. Hasan and L. J. Wade 2002 Penetration of hardpans by rice lines in the rainfed lowlands. Field Crop Res, 76: $175-188$

Thanh, N. D., H. G. Zheng, N. V. Dong, L. N. Trinh, M. L. Ali and H. T. Nguyen 1999 Genetic variation in root morphology and microsatellite DNA loci in upland rice (Oryza sativa L.) from Vietnam. Euphytica, 105: 43-51

Veen, B. W. 1982 The Influence of Mechanical Impedance on the Growth of Maize Roots. Plant and Soil, 66: 101-109

Yoshida, S. H. 1982 The rice root systems: its development and function. In: Drought resistance in crop with emphasis on rice. International Rice Research Institute. Lobanos, Philippines., 97-114

Yu, L. X., J. D. Ray, J. C. Otoole and H. T. Nguyen 1995 Use of Wax-Petrolatum Layers for Screening Rice Root Penetration. Crop Sci, 35: 684-687

Zheng, H. G., R. C. Babu, M. S. Pathan, L. Ali, N. Huang, B. Courtois and H. T. Nguyen 2000 Quantitative trait loci for root-penetration ability and root thickness in rice: comparison of genetic backgrounds. Genome, 43: 53-61 